\title{
Erratum to: A spectroscopic method to estimate the binding potency of amphiphile assemblies
}

\author{
D. R. Gauger - V. V. Andrushchenko $\cdot$ P. Bouř • \\ W. Pohle
}

Published online: 21 August 2010

(C) Springer-Verlag 2010

\section{Erratum to: Anal Bional Chem \\ DOI 10.1007/s00216-010-3969-0}

Unfortunately, during the production of this article a mistake occurred in the representation of the $\mathrm{N}^{+}-\mathrm{H}^{\cdots} \mathrm{N}^{-}$hydrogen bonds in the section 'Hydrophobicity of stearylamine' of this contribution. They should correctly read: $\mathrm{N}^{+}-\mathrm{H}^{\cdots} \mathrm{N}^{-}$.

In the 'General aspects' section as part of the 'Comparison of binding potency data' section the word orthorhombic was misspelled.

The online version of the original article can be found at http://dx.doi. org/10.1007/s00216-010-3969-0.

D. R. Gauger $\cdot$ W. Pohle $(\bowtie)$

Institute of Biochemistry and Biophysics,

Friedrich Schiller University of Jena,

Philosophenweg 12,

07743 Jena, Germany

e-mail: walter.pohle@uni-jena.de

V. V. Andrushchenko $\cdot$ P. Bour̆

Institute of Organic Chemistry and Biochemistry,

Academy of Sciences,

Flemingovo nám. 2,

16610 Prague 6, Czech Republic 